San Jose State University

SJSU ScholarWorks

Master's Projects

Master's Theses and Graduate Research

$12-1-1999$

\title{
The Effect of Pain Management Education on Nurses' Knowledge and Attitudes Regarding Opioids and Adjuvants
}

Lynne Hopper McCoy

San Jose State University

Follow this and additional works at: https://scholarworks.sjsu.edu/etd_projects

Part of the Other Nursing Commons

\section{Recommended Citation}

McCoy, Lynne Hopper, "The Effect of Pain Management Education on Nurses' Knowledge and Attitudes Regarding Opioids and Adjuvants" (1999). Master's Projects. 872.

DOI: https://doi.org/10.31979/etd.qy93-m7xm

https://scholarworks.sjsu.edu/etd_projects/872

This Master's Project is brought to you for free and open access by the Master's Theses and Graduate Research at SJSU ScholarWorks. It has been accepted for inclusion in Master's Projects by an authorized administrator of SJSU ScholarWorks. For more information, please contact scholarworks@sjsu.edu. 
THE EFFECT OF PAIN MANAGEMENT EDUCATION ON NURSES

KNOWLEDGE AND ATTITUDES REGARDING OPIOIDS AND

ADJUVANTS

A Research Study

Presented to

The Faculty of the School of Nursing

San Jose State University

In Partial Fulfillment

Of the Requirements for the Degree

Master of Science

By

Lynne Hopper McCoy, MSc, RN, OCN

Christine Hooper, EdD, RN

Phyllis M. Connolly, PhD, RN, CS

December, 1999 
THE EFFECT OF PAIN MANAGEMENT EDUCATION ON NURSES KNOWLEDGE AND ATTITUDES REGARDING OPIOIDS AND ADJUVANTS

Lynne Hopper McCoy, MS, RN, OCN

January, 2000 
Research Problem

The purpose of this study was to determine if a pain management class improved nurses' knowledge of opioid and adjuvant medications and influenced nurses' attitudes regarding pain management. Nurses in the acute care setting are responsible for assessing and managing patients in pain. Nurses respond to patients' expressions of pain and their requests for pain medication. Nurses' knowledge and attitudes regarding pain influences their ability to manage pain in patients. It is necessary for nurses to understand the pharmacology of opioid and adjuvant medication as one method of managing pain, as well as the nursing implications of each.

\section{Research Hypothesis}

Over an eleven-month period, from November 1997 to October 1998, the registered nurses (RNs) and licensed vocational nurses (LVNs) in an acute care hospital had the opportunity to voluntarily attend three different classes on pain management. The Nurses Knowledge and Attitudes Survey Regarding Pain (Ferrell \& McCaffery, 1998) was distributed in October 1997 prior to classes offered on pain management. The survey was readministered 13 months later in November 1998 after the third class. The research hypothesis is as follows:

Nurses attending one pain management educational class will score higher on the Nurses' Knowledge and Attitude Survey regarding pain than nurses who did not attend any classes.

\section{Literature Review}

It is well established that pain management is an important part of nursing. The recommendations of the Agency for Health Care Policy and Research (AHCPR) include 
use of opioids and adjuvants for pain intervention. (AHCPR, 1992; AHCPR, 1994; AHCPR, 1995). To implement the AHCPR guidelines, the California Board of Registered Nursing (BRN) published the Pain Management Policy, which states that nursing functions include providing pain relief around the clock, treating pain before the pain becomes severe, and using knowledge of equianalgesia dosages to maintain both patient safety and pain relief (BRN, 1997). In January 2000, the Joint Commission on the Accreditation of Healthcare Organizations (JCAHO) will include language in their standards that hospitals must document how pain is assessed and managed in the facility (J. Dahl, personal communication, December 9, 1998).

Fox (1982) studied nurse's attitudes, knowledge and clinical practice regarding pain management in terminally ill cancer patients. She found that nurses wanted patients to be comfortable, but their decisions on which opioid to administer demonstrated a poor understanding of how to intercede effectively in managing cancer pain.

Research by McCaffery and Ferrell over the last 10 years has focused on nurses' attitudes and knowledge regarding pain management (McCaffery, 1990; McCaffery \& Ferrell, 1992, 1999; McCaffery, Ferrell, O’Neil, Lester, \& Ferrell, 1990). McCaffery and Ferrell recently compared nurses responses in the Nurses Knowledge and Attitudes Survey Regarding Pain completed in 1989-90 to responses of nurses completing the survey in 1995. The results showed that while the 1995 group was more willing to increase the dose of pain medication by $50 \%$ in a simulated patient scenario, neither group showed a willingness to increase the dose to an effective level (McCaffery \& Ferrell, 1999). 
There are three categories of analgesics: opioids, non-steroidal anti-inflammatory drugs (NSAIDS), and adjuvants (AHCPR, 1994). McCaffery, et al. (1990) observed that nurses must understand the different categories of analgesic medications to be able to adequately relieve pain. McCaffery's suggestions include a) knowing that combining an opioid and non-opioid will improve pain relief, b) observing for respiratory depression, and c) using the World Health Organization's (WHO) analgesic ladder to guide medication use (McCaffery, et al, 1990, p. 26).

Wallace, Graham, Ventura, and Burke (1997) discussed the difficulty of implementing an educational program to improve the knowledge of nurses in an acute care setting. These authors found that pain management information is not taught in most schools of nursing and most knowledge about pain management is acquired on the job. They conclude that the "basis for decision making about pain is very weak and expertise in strategies for pain management is very limited" (p. 28). They noted that pharmacology of pain medications continues to be one of the knowledge deficits of nurses. They also noted that there is little in the literature regarding how continuing education affects knowledge levels of nurses providing pain management, thus the impetus for this study.

\section{Conceptual Framework}

The theoretical framework for this study is anchored in the concepts of Greipp's Model for Ethical Decision-Making. Greipp's Model of Ethical Decision-Making is based on general systems theory. Central to the model is the body of knowledge nurses bring to their practice. This body of knowledge is influenced by their life experience, or learned potential inhibitors (LPI), and the life experiences, or LPI's, of the patient. Learned potential inhibitors are developed from personal experience, culture, and 
personal belief system. Included in this model is the nurse's professional experience (Greipp, 1992).

Greipp's model incorporates the American Nurses Association (ANA) Code of Ethics as the primary guide for nurses in their interaction with patients. According to the Code of Ethics, nurses are responsible for correct behavior and right knowledge of pain management modalities (ANA, 1985). This concept is important when applied to pain management. Nurses use their knowledge about pain management to provide pain relief for their patients. The care nurses provide is influenced by their own life experiences as well as their experiences with patients. Preventing needless suffering is one of a nurse's responsibilities. Relief from pain is the goal for both the patient and the nurse.

To illustrate how these factors interact, consider the example of the nurse caring for an older adult with back pain from degenerative disc disease. The nurse assesses the patient and discovers that the pain has caused limited mobility and poor quality of life for the patient. The patient has been reluctant to take medication to help relieve the pain. The nurse uses knowledge of the patient's diagnosis and pain management to develop treatment options and help the patient become comfortable. Influencing this process may be the patients concerns regarding addiction to medications, or her concern that the medications will not work. In addition, the nurse may have had experiences with older adults who did not tolerate opioid medications. Professional and life experiences will influence the plan of care and the patient outcomes.

\section{Methodology}

The purpose of this study was to evaluate the effectiveness of formal education classes on nurses' knowledge and attitudes regarding pain management. The design was 
quasi-experimental using pretest-posttest intervention (classes). Permission was granted by the acute care institution to use the survey results. Exemption from Human Subjects Review was obtained from San Jose State University. A number was assigned to each survey to maintain confidentiality. The key with matched names and numbers was kept in a locked file at the acute care facility.

Nurses knowledge and attitudes were measured by scores on the Nurses Knowledge and Attitudes Survey Regarding Pain (Ferrell \& McCaffery, 1998). The survey had 39 questions, 12 of which directly assessed nursing knowledge about opioids and adjuvants. The survey was first administered in October 1997 prior to classes on pain management. The survey was administered again in November 1998 after three different pain classes were offered.

The pain management classes were offered in the form of an all day class, given on three separate days, November 5, 1997; February 12, 1998; and November 2 and 4, 1998. The third class was offered twice to allow more staff members to attend. Each pain class addressed different topics on pain management and included a lecture on use of pain medications. The topics included use and dosing of opioids, pharmacology of opioids, managing the side effects of opioids, and use of adjuvant drugs. Special considerations for different patient populations were discussed.

Setting

The survey was distributed to RN's and LVN's working in a 400-bed acute care district hospital in a suburban community in Northern California. The hospital was not affiliated with any teaching institutions. 
Sample

The surveys were distributed to the RN's and LVN's on the medical, surgical, telemetry, critical care, psychiatric, maternity and pediatric units. Seventy-seven RN's and six LVN's completed both surveys. Thirty-three of the participants attended one of the pain management classes. Four attended two classes, three attended three pain classes, and eight attended a pain management class other than the ones referred to in this study. These 15 people were eliminated from the survey sample. Therefore, the sample consisted of 68 participants ( $67 \mathrm{RNs}$ and $1 \mathrm{LVN}$ ). The sample was divided into two groups. Group A consisted of 33 participants who attended a pain class and Group B had 35 participants who attended no classes on pain management.

Procedure

The Nurses Knowledge and Attitude Survey Regarding Pain was first distributed to the nurses in October 1997. The survey was distributed again in November, 1998. Both times, the nurses were given 10 days to complete and return the survey. A number was assigned to each survey to maintain confidentiality of each participant. Participation was voluntary. A reward of candy was provided to the nursing units after surveys were returned.

\section{Instrument}

The instrument used in this study, the Nurses' Knowledge and Attitudes Survey Regarding Pain, was developed in 1987. The survey was designed as an evaluation tool to measure nurses' knowledge and attitudes about pain. It consists of 22 true-false questions and 17 multiple-choice questions. Four of the multiple-choice questions focus on two patient care scenarios. The two scenarios describe two 25-year-old males, Andy and Bob, 
on their second day after abdominal surgery. Both patients have vital signs within normal limits and both describe their pain intensity as "4" on a scale of 0 to 5 , with 0 being no pain and 5 being the worst pain. The difference between the two patients is that one, Andy, has been smiling and joking, while Bob, the second, is grimacing. The nurse is asked to rate each patient's pain and determine an appropriate dose of pain medication.

McCaffery and Ferrell established reliability and validity of this tool. Content was derived using the pain management guidelines from the AHCPR, the American Pain Society (APS) and the World Health Organization (WHO). A panel of pain experts established the content validity. The survey was administered to nurses with various levels of experience in nursing and in pain management to establish construct validity. The survey discriminates between levels of expertise. Test-retest reliability was established $(r>.80)$ by repeat testing in continuing education settings. Internal consistency reliability was established (alpha $r>.70$ ) as the survey items reflect both knowledge and attitude domains (Ferrell \& McCaffery, 1998).

\section{Data Analysis}

The data were analyzed by comparing the difference between the pretest score and posttest score of those who took one class as compared to those who did not take the classes. The gain t-test was used to determine statistical significance.

Results

Eighty-three nurses participated in both pre and posttest surveys; 77 RN's and 6 LVN's. Thirty-three of the participants attended one of the classes offered on pain management. Those that attended more than one class were eliminated from the sample. Thirty-five participants attended no classes. The sample consisted of two groups, the 33 
participants that had attended one pain management class, Group A and the 35 participants who attended no education classes, Group B. See Table 1.

The overall knowledge gained was determined by a two-tailed t-test using the number of questions correctly answered on the survey. The difference between the number correct on the pretest and the posttest is referred to as the knowledge gain score. Group A showed a mean knowledge gain score of 5.18 while Group B was 1.31. The difference in the knowledge gain scores was statistically significant at .001 with $p$ significant at $<.05(t=3.436, d f=66, p=.001)$.

\begin{tabular}{|c|c|c|c|}
\hline Group & N & $\begin{array}{c}\text { Mean } \\
\text { (Number of }\end{array}$ & Std. Deviation \\
& & $\begin{array}{c}\text { correct } \\
\text { answers) }\end{array}$ \\
\hline A & 33 & 5.18 & 4.45 \\
\hline B & 35 & 1.31 & 4.81 \\
\hline
\end{tabular}

Table 1: Knowledge Gain of Group A and Group B

In the case scenario portion of the survey nurses were asked to rate pain and determine a dose of pain medication for two different patients. For the first patient scenario, Group A responded correctly $66.6 \%$ of the time on the pretest and Group B 77.1\% of the time. Posttest scores for Group A were 87.8\% and for Group B were 85.7\%. Group A showed a greater improvement in scores on the first patient scenario, 21.2\% than did Group B, 8.6\%. Pretest - posttest data for the second patient scenario were not available due to clerical error. See Table 2. 


\begin{tabular}{|c|c|c|c|c|c|c|}
\hline & \multicolumn{2}{|c|}{ Nurses Rating of Andy 's Pain } & \multicolumn{3}{c|}{ Amount of Morphine } \\
& $\begin{array}{c}\text { Pretest } \\
\text { Score }\end{array}$ & $\begin{array}{c}\text { Posttest } \\
\text { Score }\end{array}$ & Gain & $\begin{array}{c}\text { Pretest } \\
\text { Score }\end{array}$ & $\begin{array}{c}\text { Posttest } \\
\text { Score }\end{array}$ & Gain \\
\hline Group A & $66.6 \%$ & $87.8 \%$ & 21.2 & $48.4 \%$ & $60.6 \%$ & 12.2 \\
\hline Group B & $77.1 \%$ & $85.7 \%$ & 8.6 & $57.1 \%$ & $60.0 \%$ & 2.9 \\
\hline
\end{tabular}

Table Two: Comparison of case scenario pretest-posttest answers for Groups A and B.

Limitations

There are several limitations to this study. First, the use of a non-random sample limits generalizability to other populations. Second, the years and types of nursing experience were not controlled for. Third, the history of events that occur between the pre and posttest surveys may affect the results such as increased awareness in the hospital about pain management due to the activity of pain management committee. Fourth, administering the same survey twice may effect the results by increasing awareness.

Discussion

Nurses that attended one pain management educational class scored significantly higher on the Nurses Knowledge and Attitude Survey Regarding Pain than the nurses who did not attend any classes. While scores for both groups improved, Group A showed a significantly greater improvement during the thirteen-month interval between nursing surveys. The higher pretest scores of Group B suggests that nurses in this group believed that they knew about pain management and did not need to attend classes.

The "Andy" scenario demonstrates a patient who is able to smile, has vital signs within normal limits, but states his pain is at a level 4 out of 5 . This scenario asks the nurse to rate Andy's pain and determine how much pain medication he/she would give 
Andy based on an order of morphine 5-15mg Q3-4 hours PRN pain relief. Both Group A and Group B improved their scores in the posttest and there was little difference between the two groups in the percentage correct on the posttest. Group A had a higher percentage increase on both case scenario questions than did Group B.

This is congruent with the findings of McCaffery and Ferrell (1999). They found that over a period of five years that nurses had improved their understanding of the basic pain management principles. However, nurses' were still influenced by patient's behavior when providing treatment for pain (p.50). Sixty percent of the nurses in both Groups A and $B$ answered the case scenario question correctly to increase the pain medication by $50 \%$. Group A had a knowledge gain of 12.2 points. Those that attended the class improved their understanding of pain management principles. Group B appeared to have a basic understanding of pain management principles already. Their score improved by three percentage points.

Greipp's Model of Ethical Decision Making focuses on the body of knowledge nurses bring to their practice. This body of knowledge is influenced by both experience and education. This study demonstrates how continuing education made a significant difference in the nurses understanding of pain management principles. However, this study also demonstrates that education alone does not ensure that the principles of pain management are put in to practice. At least $85 \%$ of the nurses in both Group A and Group B had learned that the patient's pain is "What the patient says it is" (McCaffery \& Pasero, 1999 , p. 17). However only $60 \%$ of the participants in both groups were willing to give an adequate amount of pain medication to "Andy" to relieve his pain. This response is congruent with Greipp's Model indicating that personal beliefs and personal experiences 
influence nurses. Nurses need more than education to transfer to practice what is learned in a class setting.

\section{Conclusions/Recommendations}

The data from this study show that continuing education increases nurses' knowledge about pain management. Nurses retain what is learned in a class setting, however how they utilize this knowledge needs further study. Clearly, there is room for improving implementation of the principles of pain management. More than $85 \%$ of the respondents rated the patient's pain correctly. However, only $60 \%$ of the respondents correctly identified the amount of pain medication to be given. This identifies a problem in transferring knowledge into practice. Future classes on pain management should include a component where the attendees can practice pain management principles. This could be done by discussing case studies and by discussing personal experiences with pain and it's management. In the area of improving pain management more than just classes are needed.

\section{Reference List}

American Nurses' Association. (1985). Code for Nurses with Interpretive Statements. Kansas City, MO: Author.

Board of Registered Nursing. (1997). Pain Management Policy (NPR-8-09). Sacramento, CA: Author.

Ferrell, B. R., \& McCaffery, M. (1998). Pain Knowledge and Attitudes Tool [Online]. Available: http://maydav.coh/Instruments/k\&a.htm 
Fox, L. S. (1982). Pain management in the terminally ill cancer patient: An investigation of nurses' attitudes, knowledge, and clinical practice. Military Medicine, 147, $455-460$.

Greipp, M. E. (1992). Undermedication for pain: An ethical model. Advances in Nursing Science, $15,44-53$.

McCaffery, M. (1990). Nurses lead the way to new priorities. American Journal of Nursing, 90(10), 45-49.

McCaffery, M., \& Ferrell, B. R. (1992). Opioid analgesics: Nurses' knowledge of doses and psychological dependence. Journal of Nursing Staff Development, 8, 77-84.

McCaffery, M., \& Ferrell, B. R. (1999). Opioids and pain management: What do nurses know? Nursing99, 29, 48-52.

McCaffery, M., Ferrell, B., O’Neil, E., Lester, M. \& Ferrell, B. (1990). Nurses' knowledge of opioid analgesics and psychological dependence. Cancer Nursing, 13,2127.

McCaffery, M. \& Pasero, C. (1999). Pain: Clinical manual ( $2^{\text {nd }}$ ed.). St. Louis: Mosby.

U.S. Department of Health and Human Services. (1992). Acute pain management: Operative or medical procedures and trauma (AHCPR Publication No. 92-0032). Rockville, MD: Author.

U.S. Department of Health and Human Services (1994). Management of cancer pain (AHCPR Publication No. 94-0592). Rockville, MD: Author.

U.S. Department of Health and Human Services (1995). Acute low back problems in adults (AHCPR Publication No. 95-0642). Rockville, MD: Author. 
Wallace, K. G., Graham, K. M., Ventura, M. R., \& Burke, R. (1997). Lessons learned in implementing a staff education program in pain management in the acute care setting. Journal of Nursing Staff Development, 13,24-31. 


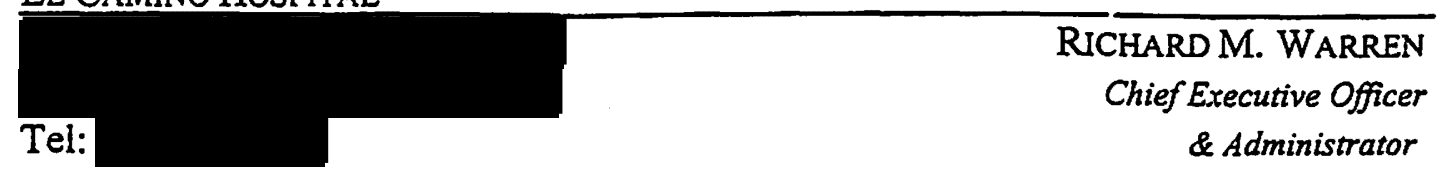

May 6, 1999

Lynne McCoy, RN

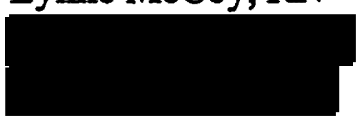

Dear Lynne:

It is my understanding that you wish to use the data collected in 1997 and 19998 from the Nurses Knowledge and Attitudes Survey Regarding Pain to determine if the education offered as a result of the initial survey made an improvement in the nurses knowledge or impacted their attitudes regarding pain. The data provided will in part fulfill the requirements of yours Master's project through the School of Nursing at San Jose State University. On behalf of El Camino Hospital I am requesting the results of your project be shared with our nursing staff.

I have reviewed the data collection tables from the survey. They meet this institution's requirement for confidentiality. I formally indicate the willingness of this institution to make available to you the survey data for your project.

Sincerely,

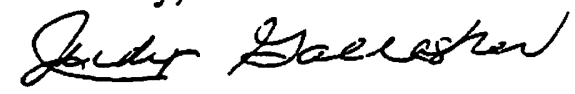

Judy Gallagher, RN, MS

Director, Medical/Surgical Services

JG:aj 
TO:

Lynne Hopper McCoy

\section{San JoséState}

UNIVERSITY

Office of the Academic Vice President

Associate Vice President Graduate Studles and Research One Washington Square San Jose. CA 95192-0025 Voice: $408 \cdot 924 \cdot 2480$ Fax: 408-924-2477 E-mall: gstudies@wahoo.sjsu.edu http://www.sjsu.edu

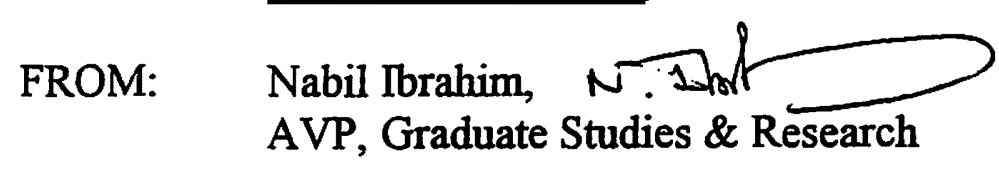

DATE: $\quad$ October 29, 1999

The Human Subjects-Institutional Review Board has approved your request to use human subjects in the study entitled:

\section{"Nurses' Knowledge and Attitudes Survey Regarding Pain"}

This approval is contingent upon the subjects participating in your research project being appropriately protected from risk. This includes the protection of the anonymity of the subjects' identity when they participate in your research project, and with regard to any and all data that may be collected from the subjects. The Board's approval includes continued monitoring of your research by the Board to assure that the subjects are being adequately and properly protected from such risks. If at any time a subject becomes injured or complains of injury, you must notify Nabil Ibrahim, Ph.D., immediately. Injury includes but is not limited to bodily harm, psychological trauma and release of potentially damaging personal information.

Please also be advised that all subjects need to be fully informed and aware that their participation in your research project is voluntary, and that he or she may withdraw from the project at any time. Further, a subject's participation, refusal to participate, or withdrawal will not affect any services the subject is receiving or will receive at the institution in which the research is being conducted.

If you have any questions, please contact me at 


\title{
ABSTRACT \\ THE EFFECT OF PAIN MANGEMENT EDUCATION ON NURSES KNOWLEDGE AND ATTITUDES REGARDING OPIOIDS AND ADJUVANTS
}

\author{
By Lynne Hopper McCoy
}

The purpose of this research was to determine if a pain management class improved nurses' knowledge and influenced nurses' attitudes regarding pain management. The design was quasi-experimental using pretest-posttest intervention. 83 participants completed the Nurses Knowledge and Attitude Survey Regarding Pain twice. Those who attended a class showed improvement in their pain management knowledge and attitude scores on the survey. Implications for staff development and inservice educators are that continuing education increases nurses knowledge about pain management and must include opportunities for class members to apply concepts. 